\title{
A política científica e tecnológica brasileira: três enfoques teóricos, três projetos políticos
}

Rafael Dias ${ }^{1}$

Renato Dagnino ${ }^{2}$

\begin{abstract}
Resumo: A matriz analítico-conceitual que marcou a política científica e tecnológica após a $2^{\text {a }}$ Guerra Mundial está associada à concepção linear da relação entre ciência, tecnologia e desenvolvimento. Ainda hoje, essa concepção mantém sua força dentro da esfera da política científica e tecnológica. Existem, contudo, três enfoques que se propõem a questionar essa visão: o enfoque evolucionário (comumente tido como o único enfoque crítico), o pensamento latino-americano em ciência, tecnologia e sociedade (PLACTS) e o que aqui chamamos de visão alternativa. O trabalho se propõe a analisar brevemente cada um desses enfoques estilizados, estabelecendo algumas conexões entre essas diferentes visões da relação ciência-tecnologia-desenvolvimento e projetos políticos igualmente distintos.
\end{abstract}

Palavras-chave: política científica e tecnológica; enfoque evolucionário PLACTS; visão alternativa.

\section{Brazilian scientific and technological policies: three theoretical approaches, three political agendas}

Abstract: The analytical and conceptual matrix that marked scientific and technological policies after World War II is associated with a linear perspective on the relations between science, technology and development. This view is still popular among policy makers. There are, however, three approaches that criticize this particular view: the Evolutionary approach, the Latin American Thought in Science, Technology and Society (PLACTS), and what we call the Alternative View. In this paper, we argue that Latin American science and technology policy

1 Doutorando do Programa de Pós-Graduação em Política Científica e Tecnológica da Unicamp. E-mail: rafaeldias@ige.unicamp.br

2 Professor Titular do Departamento de Política Científica e Tecnológica da Unicamp. E-mail: rdagnino@ige.unicamp.br 
can be better understood by modelling these three distinct approaches, and that it is possible to make an association between them and some specific interests, which are linked to different political projects.

Key-words: science and technology policy; Latin America; evolutionary approach; PLACTS; alternative view.

JEL: $\mathrm{O} 2$

\section{Introdução}

A matriz analítico-conceitual que marcou a política científica e tecnológica após a $2^{\mathrm{a}}$ Guerra Mundial está associada à concepção linear da relação entre ciência, tecnologia e desenvolvimento. Ainda hoje, essa concepção mantém sua força dentro da esfera da política científica e tecnológica.

Existem, contudo, três enfoques que se propõem a questionar essa visão: o enfoque evolucionário (comumente tido como o único enfoque crítico), o pensamento latino-americano em ciência, tecnologia e sociedade (PLACTS) e o que aqui chamamos de visão alternativa.

O enfoque evolucionário parte de formulações teóricas geradas nos países centrais e representa o mais difundido dos três. Seu foco analítico é centrado na figura da empresa e destaca o papel das inovações tecnológicas como principais elementos promotores do desenvolvimento econômico e social.

O PLACTS representa uma corrente de pensamento autônoma e original da América Latina e que, apesar de remeter às décadas de 1960 e 1970, ainda se mostra bastante atual. Reconhece a existência de obstáculos estruturais, determinados historicamente, ao desenvolvimento da América Latina, e destaca a importância de elementos como a constituição de projetos nacionais e a identificação de demandas cognitivas como orientação para as atividades científicas e tecnológicas.

A visão alternativa, por sua vez, busca constituir uma crítica de esquerda dentro do campo da política científica e tecnológica, valorizando o papel de atores como os movimentos sociais e a classe trabalhadora. Partindo das contribuições da teoria crítica da ciência e da tecnologia apresentada por Feenberg (1991), esse enfoque incorpora as críticas às visões da neutralidade da ciência e do determinismo tecnológico e as contribuições do PLACTS, em uma tentativa de propor uma abordagem mais aderente à realidade dos países latino-americanos. 
Este artigo pretende mostrar que a política científica e tecnológica latino-americana pode ser entendida a partir de uma modelagem desses distintos enfoques. $\mathrm{E}$, mais que isso, que é possível fazer uma associação entre os referidos enfoques e alguns interesses específicos, que se traduzem em diferentes projetos políticos.

\section{O questionamento do primeiro elo da cadeia linear nos países centrais: o enfoque evolucionário}

Um diagnóstico muito forte acerca da relação entre ciência, tecnologia e desenvolvimento feito pelos policy makers está relacionado às contribuições do enfoque evolucionário. Esse aspecto pode ser notado, por exemplo, na política de estímulo a parques e pólos tecnológicos, que têm como objetivo central a criação de ambientes propícios ao desenvolvimento tecnológico ou, ainda, no foco quase que exclusivo das políticas industrial e científica e tecnológica nos setores da alta tecnologia

O enfoque evolucionário representa o mais difundido dentre os três a serem explorados aqui. De fato, existe uma assimetria muito significativa entre esse enfoque em particular e os demais, tanto no âmbito das políticas públicas da área de ciência e tecnologia quanto no ambiente acadêmico. Em virtude dessa assimetria, os adeptos do enfoque evolucionário freqüentemente se colocam como os únicos a criticar a visão ofertista linear (a idéia de que mais ciência gera mais tecnologia e que isso, por sua vez, é condição suficiente para alavancar o desenvolvimento socioeconômico), o que não é verdade.

O enfoque evolucionário tem como fonte primária de inspiração os trabalhos de Schumpeter $(1984,1988)$, também incorporando as contribuições de autores posteriores, como Richard Nelson, Sidney Winter, Christopher Freeman, Giovanni Dosi e Nathan Rosenberg.

Uma das características mais relevantes acerca do enfoque evolucionário é referente à sua preocupação em relação às mudanças de longo prazo do sistema capitalista, expressa pela idéia de "evolução" desse sistema (Kwasnicki 2003). As contribuições desse enfoque se contrapõem, portanto, à teoria ortodoxa do desenvolvimento econômico, que se mostra insuficiente para oferecer uma explicação adequada acerca da dinâmica de desenvolvimento das economias modernas. As principais deficiências da teoria ortodoxa podem ser notadas em três aspectos centrais, referentes às características e comportamentos das firmas individuais, à natureza do processo de mudança tecnológica e ao papel das instituições como elementos que podem influenciar os padrões de comportamento dos agentes econômicos (López 1996). O enfoque evolucionário busca suprir essas lacunas deixadas pela teoria ortodoxa. 
De acordo com o enfoque evolucionário, as inovações tecnológicas representam o elemento que impulsiona o desenvolvimento do sistema capitalista, conforme destacado por Schumpeter (1988). Assim, esse processo é condicionado por elementos endógenos, papel desempenhado pelas inovações. Dessa idéia decorre que o foco analítico do enfoque evolucionário é a empresa privada, uma vez que, nos países centrais, de fato é esse o ator responsável pela inovação, idéia questionável no caso dos países latino-americanos.

Ligada a essa interpretação está a idéia de "destruição criativa", também apresentada por Schumpeter (1984). Segundo essa percepção, a concorrência capitalista ocorreria efetivamente por meio das inovações tecnológicas, que destruiriam a estrutura econômica antiga e criariam uma nova, superior à estrutura precedente. Esse conceito ilustra o caráter determinista-tecnológico ${ }^{3}$ do enfoque evolucionário, presente também na interpretação de Dosi (1982) e de Freeman e Perez (1988), acerca dos paradigmas tecnológicos.

Segundo López (1996), o enfoque evolucionário incorpora algumas idéias e conceitos da economia (contribuições da teoria da firma, incerteza, natureza mutável dos processos de mercado, entre outros) e faz uma série de analogias envolvendo a biologia (mecanismos de seleção, mutações, hereditariedade etc.). Ainda de acordo com López (1996), esse enfoque está apoiado em um conjunto de microfundamentos baseados em processos de aprendizagem e de seleção que envolvem agentes heterogêneos e de racionalidade limitada e que operam em ambientes complexos e não-estacionários.

No que se refere especificamente às políticas públicas, a visão evolucionária considera dois aspectos principais. O primeiro deles refere-se à importância conferida ao aprendizado em seu sentido amplo (individual, organizacional e interorganizacional), que depende fortemente da cooperação entre os atores sociais. O segundo aspecto envolve o reconhecimento de que um conjunto de políticas públicas conscientes e coordenadas são essenciais para a promoção de atividades intensivas em conhecimento em todos os setores, tendo como objetivo explícito melhorar as capacidades das firmas e, por meio disso, possibilitar ganhos de competitividade (Havas 2004).

Apesar dos estudos evolucionários terem se aprofundado consideravelmente na discussão acerca da tecnologia e seu papel dentro da soci- 
edade capitalista, curiosamente essa corrente tem se preocupado muito pouco com o entendimento da atividade científica e de seus determinantes sociais.

A visão do enfoque evolucionário está atrelada à concepção do "senso comum" acerca da ciência e da tecnologia, segundo a qual qualquer avanço científico e tecnológico é desejável, uma vez que tais avanços estariam na base do desenvolvimento capitalista (Schumpeter 1988). Deve-se atentar para o fato de que o enfoque evolucionário trata os conceitos de desenvolvimento econômico e desenvolvimento capitalista como sinônimos, idéia também presente na visão do "senso comum". Assim, pode-se afirmar que esse enfoque tem como preocupação o desenvolvimento capitalista, ao contrário do PLACTS e da visão alternativa, marcados pela preocupação para com a adoção de estilos alternativos de desenvolvimento. Essa colocação pode parecer banal a princípio, mas não é, de forma alguma, irrelevante. A aceitação da idéia de que o capitalismo é o único estilo de desenvolvimento viável implica, simultaneamente, a exclusão de qualquer discussão sobre estilos alternativos de desenvolvimento, preocupação que está na base da visão alternativa ${ }^{4}$ e que permeia também as idéias do PLACTS (que embora não questione a essência do capitalismo, busca mecanismos que possam atenuar os aspectos negativos ligados a esse modo de produção).

Bozeman \& Sarewitz (2005) questionam a validade de argumentações fundamentalmente econômicas (como é o caso do enfoque evolucionário) no que se refere a políticas tecnológicas e, particularmente, a políticas científicas. Apoiadas exclusivamente em argumentos de caráter econômico, essas políticas são afastadas de questões de conteúdo político ("por quê?”, "para quê?”, "para quem?” etc.), de relevância fundamental. Para os autores, a crença de que os investimentos em ciência e tecnologia trarão somente benefícios para a sociedade justifica a preocupação exclusiva com a geração de mais ciência e mais tecnologia. Reconhecer os aspectos negativos vinculados ao avanço científico e tecnológico seria, portanto, o primeiro passo no sentido de incorporar outros tipos de valores ao processo decisório na esfera da política científica e tecnológica.

O enfoque evolucionário não questiona a relação entre o avanço tecnológico e o desenvolvimento econômico e social, proposta pelo enfoque linear. A crítica feita pelos adeptos dessa visão é restrita ao primeiro elo da cadeia linear de inovação, ou seja, à relação entre o desenvolvimento científico e o desenvolvimento tecnológico. Portanto, o avanço tecnológico (representado pelas inovações tecnológicas)

4 De fato, essa percepção impõe uma barreira intelectual significativa. Está presente, por exemplo, nas discussões acerca de estratégias para o desenvolvimento sustentável, dentro das quais o próprio modo de produção capitalista raramente é questionado. 
continua sendo, para a abordagem evolucionária, condição suficiente para a promoção do desenvolvimento econômico e social 5 .

A relação existente no primeiro elo da cadeia, segundo o enfoque evolucionário, entre o avanço científico e o avanço tecnológico, seria sistêmica, em contraposição à visão linear, que reconhece apenas a relação de causalidade que parte do avanço científico. Porém, para esse enfoque, a relação entre os demais elos da cadeia seria linear. Em geral, as críticas do enfoque evolucionário ao modelo ofertista linear estão mais centradas no fato desse último não ter seu foco na figura da empresa do que na concepção ofertista linear propriamente dita.

Dentro da perspectiva do enfoque evolucionário, o avanço científico é freqüentemente entendido como uma condição suficiente para a promoção do avanço tecnológico. Contudo, sugere este enfoque, isso não estaria ocorrendo na prática nos países latino-americanos, uma vez que o macroambiente econômico e institucional estaria inibindo o surgimento de inovações tecnológicas. Dessa maneira, o foco das recomendações de políticas que partem do enfoque em questão é voltado justamente para a criação de um elo entre o avanço científico e o avanço tecnológico. A figura 1 abaixo sintetiza o diagnóstico oferecido por essa visão.

FIGURA 1. A VISÃO DO ENFOQUE EVOLUCIONÁRIO

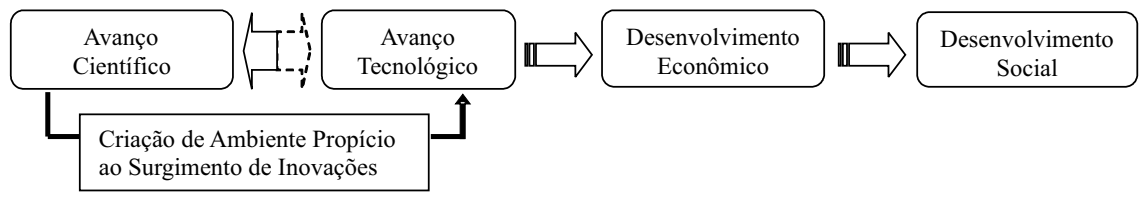

Fonte: elaboração própria.

O enfoque evolucionário, ao contestar o primeiro elo da cadeia linear de inovação, critica o modelo tradicional de oferta e demanda (technology push e demand pull). No plano teórico, essas críticas podem ser observadas, por exemplo, nos trabalhos de Dosi et al. (1988) e de Nelson (1994).

A preocupação do enfoque evolucionário no que diz respeito ao primeiro elo da cadeia linear de inovação pode ser verificada na prática por meio das tradicionais recomendações de políticas de estímulo à relação universidade-empresa. Nesse sentido, Etzkowitz \& Leydesdorff (1997) afirmam que a constituição de uma "hélice tripla" de relações entre aca-

5 A idéia de que as inovações tecnológicas representam a força endógena que movimenta o desenvolvimento capitalista permeia todo o trabalho de Schumpeter (1988). 
demia, setor produtivo e governo representa um componente essencial de qualquer estratégia inovativa, nacional ou multinacional.

Assim, para o enfoque evolucionário, para que o avanço científico possa efetivamente se converter em avanço tecnológico (e, assim, alavancar o desenvolvimento econômico e social) se faz necessária a constituição de um ambiente propício ao surgimento de inovações, que pode ser alcançada por meio de reformas econômicas e institucionais.

Essa é, portanto, a visão evolucionária acerca do descasamento entre as esferas de produção e uso do conhecimento. Passemos, pois, ao segundo diagnóstico a ser apresentado: o do PLACTS.

\section{Dependência, projeto nacional e demandas cognitivas: o pensamento latino-americano em ciência, tecnologia e sociedade (PLACTS)}

O segundo diagnóstico apresentado no presente trabalho refere-se ao pensamento latino-americano em ciência, tecnologia e sociedade. A grande maioria dos pensadores que compunham o PLACTS partiu principalmente da área de ciências "duras" e de engenharias. Entre os principais expoentes dessa corrente estão Amílcar Herrera, Jorge Sábato, José Leite Lopes, Francisco Sagasti e Osvaldo Sunkel (Vaccarezza 2003). Oscar Varsavsky é geralmente incluído dentro do PLACTS puramente por uma questão de contemporaneidade, uma vez que suas idéias claramente demonstram maior afinidade com as da Visão Alternativa.

O PLACTS surgiu em meados da década de 1960 a partir de dois fenômenos paralelos. Em primeiro lugar, deve ser destacada a importância dos movimentos sociais que marcaram os anos 1960 e 1970 , como, por exemplo, manifestações pelos direitos civis e pelo meio ambiente, críticas ao consumismo exacerbado, movimentos contra as mudanças no trabalho acarretadas pela crescente automação nas fábricas, preocupações relativas à pesquisa genética e à utilização da energia nuclear etc. (Cutcliffe 2003). Esses movimentos expressavam o descontentamento e a crescente desconfiança da sociedade em relação a distintos problemas, dentre os quais, aqueles ligados à ciência e à tecnologia. Como resposta acadêmica a esses movimentos, foi consolidado o campo de estudos em ciência, tecnologia e sociedade nos EUA e na Europa, que tem como enfoque central uma perspectiva crítica em relação à visão clássica da ciência, essencialista (no que se refere à atribuição de propriedades ao mundo natural) e triunfalista (uma vez que a ciência é entendida como a representação suprema e definitiva da verdade objetiva) (López Cerezo 2004). Na América Latina, essas preocupações incorporaram também outras questões de caráter local, dando forma ao 
pensamento latino-americano em ciência, tecnologia e sociedade das décadas de 1960 e 1970.

Um segundo elemento que levou à formação do PLACTS foi o descontentamento de parte da comunidade de pesquisa frente às recomendações de política pregadas pelos organismos internacionais, em especial pela Organização das Nações Unidas para a Educação, a Ciência e a Cultura (Unesco), pelo Banco Interamericano de Desenvolvimento (BID) e pela Organização dos Estados Americanos (OEA) ${ }^{6}$. Essas recomendações apresentavam uma estreita relação com a visão linear da relação entre ciência, tecnologia e desenvolvimento, presente no Relatório Bush?

O PLACTS guarda estreitos laços com as contribuições da teoria da dependência e da Comissão Econômica para a América Latina e o Caribe (Cepal). Em relação à primeira, compartilhava, sobretudo, das preocupações ligadas aos elementos estruturais determinados historicamente. Com a segunda, partilhava da esperança depositada nos modelos de planificação econômica, remotamente inspirados pela experiência do bloco soviético.

Dagnino et al. (1996) apontam para uma relativa homogeneidade (ou unidade) dentro do PLACTS. A respeito dos vínculos internacionais, observa-se uma forte dinâmica de relações latino-americanas, mas pouca relação com os estudos desenvolvidos em outras regiões, a exemplo do que se verificava no restante do campo ciência, tecnologia e sociedade (CTS) na América Latina (Kreimer \& Thomas 2004).

Segundo Kreimer \& Thomas (2004), o campo de estudos CTS na América Latina nos anos 1960 e 1970 compreendia três grandes áreas temáticas, referentes a distintas "culturas disciplinares". Desse modo, os estudos estavam associados a uma abordagem histórica, a uma abordagem política ou a uma abordagem socioantropológica. O PLACTS se encaixaria na segunda dessas abordagens, a de caráter político.

Alguns traços marcantes do PLACTS, conforme destaca Vaccarezza (2003), são referentes a seu caráter original e autônomo (como matriz de pensamento legitimamente latino-americana) e à sua coerência, por ressaltar o caráter estrutural do atraso da América Latina. Dagnino et al. (1996: 20) destacam, ainda, o forte conteúdo político presente nas

6 Conforme apresenta Herrera (1973).

7 Relatório produzido por Vannevar Bush, diretor do Escritório de Pesquisa e Desenvolvimento Científico Norte-americano, a pedido do presidente Franklin D. Roosevelt. Criou a base retórica para explicar o valor da ciência e da tecnologia na sociedade moderna, garantindo que essas tivessem,

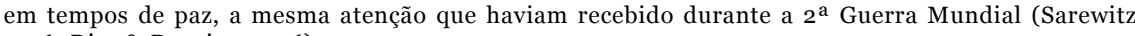
1996; Dias \& Dagnino 2006). 
contribuições do PLACTS, afirmando que, para alguns dos pensadores dessa corrente, "a política científica e tecnológica constituía uma ferramenta para a realização de tarefas revolucionárias e a consolidação do Estado socialista, para outros era um aspecto integrante de uma estratégia nacional". De fato, a grande maioria dos pensadores que compunham o PLACTS estava comprometida com a segunda visão, para a qual a PCT constitui um elemento de uma estratégia nacional maior. Independente disso, as análises do PLACTS são caracterizadas, em sua totalidade, por uma clara preocupação normativa, conforme destacam Kreimer \& Thomas (2004).

Uma preocupação comum a muitos dos autores alinhados à leitura do PLACTS remete à questão energética, interpretada como um ponto fundamental no que se refere ao desenvolvimento científico e tecnológico da América Latina e na preservação da soberania nacional por parte dos países da região. Essa preocupação pode ser notada, por exemplo, nos trabalhos de José Leite Lopes $(1964,1978)$.

Um outro traço importante do PLACTS, que o distingue principalmente do enfoque evolucionário, está ligado ao fato de que a política científica e tecnológica propriamente dita apresenta uma menor importância relativa no conjunto das políticas sugeridas pelo PLACTS. As políticas de caráter econômico (a política industrial, sobretudo) de fato assumem uma importância maior dentro das contribuições fornecidas pelo enfoque em questão.

Vaccarezza (2003) defende que o PLACTS fornece um arcabouço analítico-conceitual mais adequado do que o enfoque evolucionário no que se refere à compreensão da realidade latino-americana. Isso porque, na visão do autor, o enfoque evolucionário confere importância excessiva à inovação tecnológica e não identifica a real dimensão e os determinantes da relação de dependência, como faz o PLACTS. Além disso, o autor entende que os estudos microeconômicos com foco em experiências de empresas individuais constituem uma base inconsistente para a formulação de políticas públicas, constatação compartilhada mais recentemente por alguns autores do enfoque evolucionário.

A leitura do PLACTS acerca do enfoque da cadeia linear de inovação passa por questões relacionadas ao projeto nacional e à superação dos obstáculos histórico-estruturais relacionados ao subdesenvolvimento. A figura 2 ilustra a visão do PLACTS acerca da relação expressa pela cadeia linear de inovação. 
FIGURA 2- A VISÃO DO PLACTS

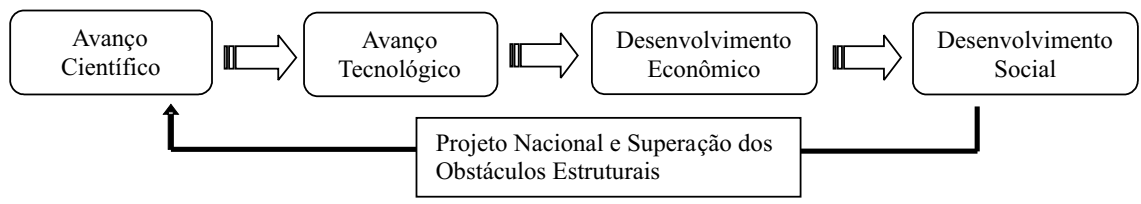

FONTE: elaboração própria.

Na visão do PLACTS, assim como na leitura do enfoque evolucionário, os elementos do contexto são considerados os determinantes sobre os quais a política científica e tecnológica deve atuar. Enquanto, para o enfoque evolucionário, os elementos relevantes do contexto são aqueles relacionados às empresas e ao ambiente no qual estão inseridas, para o PLACTS, os elementos relevantes são representados pelos obstáculos estruturais historicamente determinados, tais como a distribuição de renda e as relações de dependência, internas e externas.

Assim, dentro da concepção do PLACTS, para que o modelo da cadeia linear de inovação possa se concretizar na prática seria necessária a superação dos obstáculos estruturais relacionados à condição periférica por parte dos países da América Latina. Para tanto, advogava o PLACTS, seria imprescindível a consolidação de um projeto nacional claro e coerente, que estabelecesse diretrizes para o desenvolvimento dos países latino-americanos.

A questão do projeto nacional está intimamente relacionada ao conceito de política científica implícita, apresentado por Herrera (1973). A política implícita seria a que efetivamente determina o papel da ciência na sociedade, pois expressaria a demanda científica e tecnológica (ou, ainda, cognitiva) intrínseca ao projeto nacional vigente em cada país. A outra face da política científica - a explícita - seria aquela expressa oficialmente, por meio de documentos, leis, instituições etc.

Em última instância, o Pensamento Latino-Americano em Ciência, Tecnologia e Sociedade propõe que se faça uma inversão da cadeia linear de inovação, movida por uma lógica ofertista. A construção de um projeto nacional estaria na base da constituição de uma demanda social por conhecimento, o que puxaria o avanço científico e tecnológico possibilitando, dessa forma, o desenvolvimento econômico e social dos países da América Latina.

Essa é, em linhas gerais, a visão do PLACTS acerca da debilidade da relação entre produção e uso do conhecimento. Passemos agora à última das três correntes, a visão alternativa. 


\section{A crítica à neutralidade e ao determinismo como base de um novo estilo de desenvolvimento: a visão alternativa}

O terceiro enfoque que se propõe a contestar a concepção expressa pelo modelo da cadeia linear de inovação é a que aqui chamamos de visão alternativa. Esse enfoque parte do pressuposto fundamental de que ciência e tecnologia seriam elementos carregados de valores e passíveis de serem controlados pelo ser humano. Além disso, aceita a idéia colocada por Feenberg (2003), segundo a qual um determinado padrão de ciência e de tecnologia serviria como uma espécie de moldura para um determinado estilo de desenvolvimento econômico e social.

A visão alternativa é sustentada basicamente pelas contribuições da teoria crítica da ciência e da tecnologia, de modo que se mostra conveniente apresentar, ainda que de forma breve, as principais idéias dessa corrente de pensamento. As reflexões da teoria crítica estão fortemente pautadas pelas contribuições da sociologia da ciência e da tecnologia, em particular pelo conceito de "tecido sem costuras", proposto por Hughes (1986), segundo o qual a tecnologia e os elementos sociais, políticos, econômicos e institucionais estariam imbricados de tal forma que seria inadequado analisar esses aspectos por meio de óticas separadas e independentes. Essa abordagem sociotécnica, que se propõe a observar os aspectos técnicos e os aspectos sociais a partir de uma perspectiva conjunta, representa um dos mais sólidos elementos de sustentação associados à visão alternativa.

De acordo com Dagnino et al. (2004), são três os conjuntos de abordagens baseadas na sociologia da ciência e da tecnologia que fornecem respaldo à análise sócio-técnica da teoria crítica: a de Thomas Hughes, que traz o conceito de sistemas tecnológicos; a de Michel Callon, Bruno Latour e John Law, que propõem o conceito de ator-rede; e a abordagem do construtivismo social da tecnologia, encabeçada por Trevor Pinch e Wiebe Bijker. Esses três conjuntos refutam as análises deterministas (sociais ou tecnológicas) que buscam relações explicativas monocausais entre ciência e tecnologia e a sociedade.

A abordagem da teoria crítica contrapõe-se a outras três visões a respeito da tecnologia, a saber, a do instrumentalismo, a do determinismo e a do substantivismo (Feenberg 2003; Dagnino et al. 2004). Essas visões partem de diferentes interpretações acerca de dois aspectos relacionados à tecnologia: a neutralidade e o determinismo. A figura 3, apresentada abaixo, sintetiza a forma com que essas quatro leituras interpretam essa questão. 
FIGURA 3- VISÕES DA TECNOLOGIA: NEUTRALIDADE E DETERMINISMO

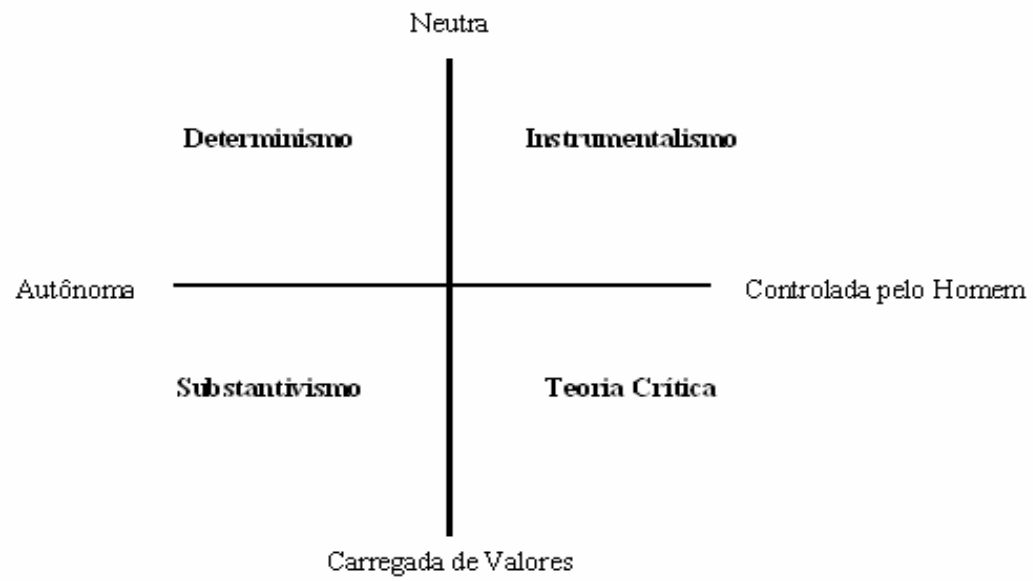

FONTE: figura adaptada a partir de Dagnino et al. (2004).

No eixo vertical, estão representadas as duas visões a respeito da neutralidade da tecnologia (neutra ou carregada de valores); no eixo horizontal, estão as visões acerca da autonomia da tecnologia (autônoma ou controlada pelo homem).

A visão do instrumentalismo representa a visão do "senso comum" (essencialista e triunfalista) a respeito da ciência e da tecnologia, também defendida por grande parte da comunidade de pesquisa. Dentro da leitura instrumentalista, a tecnologia é neutra (ou seja, não contém valores) e é controlada pelo homem. Essa concepção entende a tecnologia como um instrumento que garante o crescente bem-estar das sociedades, por meio de sucessivas melhorias de produtos e processos. Pode ser entendida, de certa forma, como uma extensão das idéias iluministas.

A maior parte da comunidade de pesquisa também compartilha da visão instrumentalista da ciência e da tecnologia. De fato, é conveniente para os pesquisadores assumirem essa postura, uma vez que, ao fazê-lo, legitimam-se frente à sociedade e isentam-se de responsabilidade por qualquer resultado negativo do avanço científico e tecnológico. Assim, a relutância da comunidade de pesquisa em abandonar a concepção instrumentalista remete a conflitos associados à terceira face do poder, aos quais Lukes (1974) chamou de latentes. Esse tipo particular de conflito ocorre quando as opiniões ou preferências da sociedade são manipuladas, prevenindo, assim, o surgimento de eventuais conflitos no fu- 
turo. Devido à sua própria natureza, a existência de tais conflitos não pode, por definição, ser comprovada. Assim, é cômodo para a comunidade de pesquisa defender a crença na ciência e na tecnologia como ferramentas que apresentam uma lógica intrínseca de funcionamento ótimo (Cutcliffe 2003), encobrindo, assim, os elementos políticos e os valores que condicionam as atividades científicas e tecnológicas.

O determinismo (associado à leitura marxista tradicional, segundo a qual o desenvolvimento das forças produtivas seria o motor da História) entende a tecnologia como uma força neutra e autônoma. A sociedade, para essa visão, é um agente passivo que deve se adaptar às mudanças impostas pelo avanço tecnológico. Assim como na visão instrumentalista, na visão do determinismo a tecnologia é entendida como algo que serve "para o bem ou para o mal", ou seja, não incorpora os valores sociais do ambiente no qual é gerada. Para essas duas visões, que partilham da concepção da neutralidade, a tecnologia encerra potenciais negativos e positivos, que são liberados apenas no momento de sua utilização.

A leitura do substantivismo, associada à Escola de Frankfurt, admite que a tecnologia é carregada de valores, mas destaca o caráter autônomo do avanço tecnológico em relação à sociedade. É, portanto, uma visão pessimista, segundo a qual a sociedade seria progressivamente submetida a valores relativos à eficiência, controle e poder, em virtude do constante avanço tecnológico.

Por fim, a quarta visão apresentada é, justamente, aquela defendida pela teoria crítica, que compreende a tecnologia como uma força carregada de valores e controlada pelo homem. A tecnologia convencional sustentaria e reforçaria os valores e a estrutura capitalista. A fim de modificar o atual estilo de sociedade e de promover alternativas de desenvolvimento efetivamente sustentáveis e que efetivamente beneficiassem à coletividade, a teoria crítica destaca a necessidade de promoção de instrumentos de democratização dos processos decisórios relativos à construção sociotécnica.

Segundo Feenberg (2003), a teoria crítica reconhece as conseqüências catastróficas do desenvolvimento tecnológico ressaltadas pelo substantivismo, mas ainda vê uma promessa de maior liberdade na tecnologia. Assim, para a teoria crítica, o problema central não estaria ligado ao avanço tecnológico em si, mas à inexistência de instituições que permitam o pleno controle humano sobre a tecnologia. Dessa maneira, para essa corrente, a democratização do processo de construção (planejamento e desenvolvimento) da tecnologia estaria na base da constituição de um modelo alternativo de sociedade. Segundo Oliveira (2002), a teoria crítica representa uma filosofia 
efetivamente "de esquerda", em contraposição a filosofias mais "à direita”, como é o caso do positivismo lógico, por exemplo.

As quatro visões apresentadas acima podem ser sintetizadas em sentenças simples, com o intuito de facilitar a compreensão de seus elementos. As idéias associadas ao instrumentalismo poderiam ser expressas, por exemplo, na sentença "armas não matam pessoas, pessoas matam pessoas”. As idéias ligadas ao determinismo, por sua vez, poderiam ser sintetizadas na frase de Marx (1985:106): “o moinho movido pelo braço humano nos dá a sociedade com o suserano; o moinho a vapor dá-nos a sociedade com o capitalista industrial”. Por trás dessa colocação está a concepção de que as mudanças dos elementos da técnica determinam as transformações das relações sociais. A visão substantivista, pessimista ao extremo, pode ser sintetizada pela sentença "somente um deus pode nos salvar da catástrofe (resultante dos efeitos negativos do avanço tecnológico)". Por fim, a teoria crítica pode ser sintetizada por uma possível réplica à idéia do substantivismo, algo como "a catástrofe é uma forte possibilidade, mas pode ser evitada por meio de mudanças tecnológicas e de mudanças sociais”.

As reflexões levantadas pela teoria crítica levam à conclusão de que a ciência e a tecnologia produzidas dentro do capitalismo serviriam apenas para sustentar um estilo capitalista de sociedade e de desenvolvimento sendo, portanto, elementos inadequados para suportar estilos alternativos de desenvolvimento econômico e social. Dessa forma, para que se pudesse construir um modelo distinto de sociedade (preocupação que une o PLACTS à teoria crítica), seria necessário um redesenho da ciência e da tecnologia. Caso não haja esse redesenho, qualquer tentativa de construção de modelos alternativos de sociedade será comprometida, de modo que o resultado efetivamente obtido estará sempre aquém da mudança inicialmente pretendida.

Para a teoria crítica, vale dizer, não se trata de uma determinação das mudanças sociais exclusivamente pelas mudanças tecnológicas. De fato, dentro dessa visão, haveria uma co-evolução entre as mudanças sociais e institucionais e as transformações científicas e tecnológicas, que se reforçariam mutuamente no sentido de promover uma transformação maior.

A estratégia de mudança do atual estilo tecnológico em direção a alternativas que confiram suporte a padrões alternativos de sociedade e de desenvolvimento deveria estar apoiada, como mostram Dagnino et al. (2004), no processo de "adequação sociotécnica" (AST), conceito esse de particular importância dentro das reflexões da visão alternativa. 
O processo da adequação sociotécnica representaria a adaptação da tecnologia convencional, carregada de valores capitalistas, de modo que o novo estilo de tecnologia pudesse incorporar outros tipos de valores e, assim, atender às demandas de toda a sociedade e não aos interesses de uma pequena parcela desta ${ }^{8}$. Em outras palavras, o processo de adequação sociotécnica envolveria a remodelagem dos artefatos e das tecnologias existentes, essencialmente capitalistas, com a finalidade de promover a convergência dos elementos técnicos aos interesses de determinados grupos sociais, em especial àqueles da classe trabalhadora, em um processo efetivamente democrático. Paralelamente, deveria haver uma co-evolução de certos elementos sociais e institucionais, no sentido de respaldar esse processo.

Se a tecnologia é resultante de um processo de constante negociação entre os atores envolvidos no processo de construção social da tecnologia, ou seja, dos grupos sociais relevantes, conforme descreve Bijker (1995), a adequação sociotécnica constitui um processo inverso, de acordo com Novaes (2005), por meio do qual a tecnologia seria adaptada de modo a atender aos interesses de outros atores sociais, distintos daqueles que foram responsáveis pela sua construção social.

Ainda segundo Novaes (2005), o conceito da adequação sociotécnica poderia ser operacionalizado em algumas modalidades distintas, a saber: (1) uso da tecnologia, (2) apropriação da tecnologia, (3) ajustes no processo de trabalho, (4) alternativas tecnológicas, (5) incorporação do conhecimento científico e tecnológico existente, (6) revitalização ou repotenciamento das máquinas e equipamentos e (7) incorporação de conhecimento científico e tecnológico novo. A adequação sociotécnica deve ser entendida, dessa forma, como um processo, conforme coloca Novaes (2005). A noção da adequação sociotécnica é diferente, portanto, das idéias derivadas do movimento da tecnologia apropriada, cujo foco principal era no "produto" (ou seja, na tecnologia pronta). Nesse sentido, o conceito da adequação sociotécnica e suas implicações normativas representam um importante instrumental no sentido de orientar as mudanças no plano científico e tecnológico, vislumbradas pela visão alternativa.

Feitas essas considerações sobre o processo da adequação sociotécnica, retomemos a argumentação acerca do debate da não-neutralidade da ciência e da tecnologia. No caso dos países latino-americanos, a visão da não-neutralidade evidencia, ainda, um outro elemento importante. Uma vez que a tecnologia empregada nesses países é oriunda dos países

8 Algo no sentido apontado por Varsavsky (1976), de substituição dos valores apoiados no individualismo e no consumismo ostensivo por outros, apoiados na solidariedade, por exemplo. 
centrais, decorre que os valores nela incorporados são, também, específicos desses países. A tecnologia se torna, portanto, um vetor que acaba por reforçar os laços de dependência da América Latina em relação aos países do Norte.

Feenberg (2003) é bastante enfático ao descrever as tensões derivadas da adoção de um padrão tecnológico que não é compatível com os valores de uma determinada sociedade, citando o emblemático caso japonês. $\mathrm{O}$ autor ressalta as tensões decorrentes do encontro entre a tradicional sociedade japonesa do século XIX e a tecnologia ocidental, proveniente da Europa e dos EUA. De fato, não se pode esperar que tensões dessa natureza ocorram na América Latina, uma vez que os valores ocidentais (europeus e, posteriormente, norte-americanos) estiveram presentes desde o descobrimento do Novo Mundo. Contudo, não se pode negar que a crescente homogeneização cultural, ao menos, em parte associada aos valores incorporados à tecnologia empregada, constitui um mecanismo importante de estreitamento das relações de dependência em relação aos países centrais.

As principais contestações da visão alternativa são voltadas à concepção instrumentalista acerca da ciência e da tecnologia. Para esse enfoque, a forma com que essa mentalidade está imbuída na sociedade constitui um forte obstáculo institucional, ou uma resistência a qualquer mudança que possa ser realizada no padrão das políticas científicas e tecnológicas ou a mudanças no próprio estilo de desenvolvimento das sociedades em geral.

A visão alternativa, apoiada pelas reflexões expostas acima, incorpora ainda elementos do enfoque evolucionário e do PLACTS. Com o intuito de apresentar de forma mais detalhada essa visão, faz-se necessário explorar um pouco mais essas noções.

São dois os elementos oriundos das contribuições do enfoque evolucionário que podem ser identificados na visão alternativa. O primeiro deles se refere à idéia de que as empresas seriam os principais atores no processo de inovação tecnológica. A visão alternativa reconhece esse argumento, mas contesta sua validade no contexto dos países latino-americanos. $\mathrm{O}$ estilo de desenvolvimento alternativo proposto por essa visão estaria apoiado em instituições de outra natureza, que não as empresas, elementos tipicamente capitalistas. Como opção às empresas, a visão alternativa propõe o estímulo a empreendimentos autogestionários, mais adequados aos valores da sociedade que esse enfoque defende.

Um segundo elemento do enfoque evolucionário que pode ser identificado na visão alternativa remete à idéia de oferta e demanda (do conhe- 
cimento), a partir da qual ambos os enfoques se desenvolvem. Porém, enquanto o enfoque evolucionário parte de um "ofertismo absoluto", isto é, da idéia de que o avanço científico e tecnológico, inerentemente positivo, traz benefícios crescentes para a sociedade, sob a forma de novos bens e serviços, a visão alternativa parte de uma idéia de "oferta antecipatória", segundo a qual caberia à comunidade de pesquisa explorar as fronteiras de conhecimento que mais se adequassem às necessidades e às demandas da sociedade.

A visão alternativa apresenta algumas semelhanças em relação ao PLACTS. A mais aparente delas pode ser observada no que diz respeito à insatisfação quanto ao padrão geral das políticas públicas de ciência $\mathrm{e}$ tecnologia.

Assim como o PLACTS, a visão alternativa questiona a concepção essencialista e triunfalista acerca da ciência e da tecnologia. Além disso, esse enfoque é marcado por uma evidente preocupação em relação aos elementos histórico-estruturais comuns aos países latino-americanos e aos problemas particulares da região, ambos ignorados pelo enfoque evolucionário.

Tanto o PLACTS como a visão alternativa são marcados pela desconfiança com que encaram a viabilidade de um estilo de desenvolvimento puxado por empresas, legitimado por uma fé cega nas livres forças de mercado. Na análise do PLACTS, o Estado aparece como o ator responsável pela indução das mudanças, idéia facilmente compreensível, levando em consideração o ambiente político latino-americano dos anos 1960 e 1970. A visão alternativa, por sua vez, partindo da crítica ao socialismo real e agregando as contribuições dos estudos construtivistas da ciência e da tecnologia, coloca menos importância no papel do Estado e enfatiza a importância da participação dos movimentos sociais como elemento indutor de mudanças (Dagnino 2000).

Um outro elemento que separa a visão alternativa do PLACTS (e também do enfoque evolucionário) remete à crítica à idéia da neutralidade da ciência, que na verdade representa um dos principais elementos desse terceiro enfoque. Apesar de conter também os elementos do enfoque evolucionário colocados anteriormente, a visão alternativa é muito mais uma tributária do PLACTS. De fato, poderia ser dito que essa visão representa uma síntese da incorporação das contribuições da teoria crítica às idéias do PLACTS.

Além de reconhecer a existência dos obstáculos estruturais ao desenvolvimento dos países latino-americanos, também apontados pelo PLACTS, a visão alternativa reconhece a existência de obstáculos de natureza institucional, relativos à concepção da comunidade de pesqui- 
sa - o ator dominante da PCT latino-americana - acerca da ciência e da tecnologia, relativos à neutralidade e ao determinismo (Dagnino 2004).

A visão alternativa incorpora ainda a idéia de Mészáros (2002), de que a tecnologia - simbolizada pela máquina - incorpora em si as relações sociais de dominação econômica. Dessa forma, o avanço da tecnologia capitalista, bem como da ciência sobre a qual está apoiada, teria um caráter intrínseco responsável pelo crescente controle do capitalista sobre o processo produtivo e pelo próprio processo de acumulação de capital. Segundo essa visão, portanto, a construção do socialismo envolveria, no longo prazo, um processo de adaptação dos meios de produção, sem a qual não poderia haver uma mudança na essência das relações de produção.

Uma argumentação semelhante pode ser encontrada nas idéias de Noble (2001). Assim como Mészáros (2002), o autor refuta a tese da nãoneutralidade da tecnologia, afirmando que a mera apropriação dos meios de produção capitalistas por parte dos trabalhadores não seria suficiente para permitir uma mudança radical das relações de produção. Mais que isso, a tecnologia capitalista representaria um obstáculo à transição para o socialismo.

Na visão de Noble (2001), fatores técnicos e econômicos teriam importância dentro do processo de avanço tecnológico. Contudo, o autor defende que os elementos determinantes desse processo seriam de natureza política. Noble (2001) destaca, ainda, o papel de cientistas e engenheiros no processo do avanço tecnológico. Segundo o autor, os próprios técnicos, envolvidos diretamente na criação de artefatos tecnológicos, reconhecem, em alguma medida, a dependência de suas atividades em relação aos detentores do capital, porém, ignoram a interferência desses interesses particulares sobre o resultado das atividades técnicas por eles desempenhadas. Para esses profissionais, portanto, apenas os fatores estritamente técnicos estariam associados à tecnologia em si.

Essas considerações são particularmente relevantes para a visão alternativa. A manifestação da visão do "senso comum" entre cientistas e engenheiros constitui um dos obstáculos, de natureza institucional, que deve ser removido a fim de que a transição para um modelo distinto de sociedade possa se concretizar. Nesse sentido, um dos mecanismos indutores de mudança defendidos pela visão alternativa consiste na introdução de disciplinas CTS em cursos de graduação nas áreas de ciências e engenharias e, no longo prazo, em transformações profundas no ensino e na forma de se fazer ciência. Assim, esse mecanismo permitiria a superação da mentalidade Instrumentalista. 
A tensão destacada nos parágrafos anteriores, entre tecnologia capitalista e tecnologia socialista, é de grande importância para o desenvolvimento das idéias da visão alternativa. Tal distinção não é muito usual, mesmo por parte dos teóricos da ortodoxia marxista. Tampouco o enfoque evolucionário ou o PLACTS fazem essa distinção. Esses enfoques abordam apenas a tecnologia: um elemento que pode ser moldado por qualquer classe social e usado para atender a um determinado objetivo ${ }^{9}$. Seu caráter intrínseco não tem qualquer influência sobre a transição da sociedade capitalista para qualquer outro tipo de sociedade.

A figura 4, abaixo, ilustra o diagnóstico da Visão Alternativa.

FIGURA 4- A VISÃO ALTERNATIVA

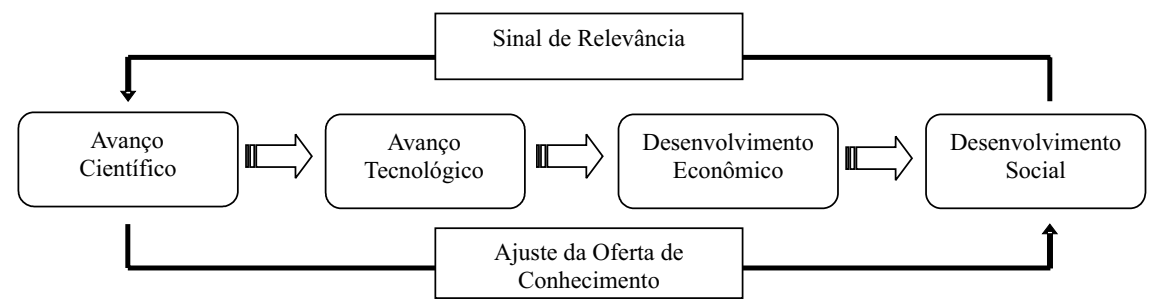

FONTE: elaboração própria.

Segundo a visão alternativa, na base do descasamento entre as esferas de geração e aplicação do conhecimento estaria a desfuncionalidade da pesquisa científica frente às demandas da sociedade (idéia presente também nas contribuições do PLACTS). Assim, para que essas duas esferas pudessem ser aproximadas em um ciclo virtuoso, seria necessária uma mudança profunda nas atividades da comunidade de pesquisa, inclusive na forma com que a ciência é produzida.

\section{Conclusão}

De um modo geral, os diagnósticos dos três enfoques partem de uma preocupação em comum: a de que haveria um desajuste entre o âmbito no qual ocorre a produção do conhecimento e o âmbito de aplicação dos conhecimentos produzidos, o que resultaria em uma debilidade da interação pesquisa-produção. Esse problema representa, de fato, a ques-

9 Para o enfoque evolucionário, em específico, a questão da luta de classes sequer parece ser relevante. 
tão central que move a política científica e tecnológica. Nos países latino-americanos, vale salientar, o descolamento entre as esferas de produção e aplicação do conhecimento adquire um caráter particularmente grave, em virtude da inserção periférica dos países da região, responsável pelo agravamento de severos obstáculos de natureza estrutural (Dagnino 2004).

Essa fratura significa, na prática, que o conhecimento gerado pelo complexo público de educação superior e de pesquisa não está sendo absorvido pelo setor produtivo e, portanto, não está sendo convertido em novos bens e serviços que poderiam trazer incrementos de bem-estar para a sociedade. Assim, esse ciclo virtuoso que, a despeito de eventuais problemas e reduções mecanicistas aos quais está submetido, legitima e impulsiona o capitalismo nos países centrais, não está ocorrendo nos países latino-americanos.

O enfoque evolucionário, gerado no contexto dos países centrais (EUA e Europa, sobretudo), apresenta preocupações fundamentalmente econômicas. Quando esse referencial analítico-conceitual é aplicado na esfera da política científica e tecnológica, sua natureza puramente econômica traz alguns problemas, conforme colocam Bozeman \& Sarewitz (2005). Outro problema fundamental que compromete a utilização desse enfoque como instrumento de apoio à formulação, à implementação e à avaliação de políticas remete ao fato do foco adotado nas análises evolucionárias ser essencialmente microeconômico, conforme coloca Vaccarezza (2004).

O enfoque proposto pelo PLACTS, por representar uma corrente original e autônoma da região, mostra-se mais próximo dos reais problemas colocados pelo processo histórico de inserção periférica dos países da América Latina. Por identificar os elementos estruturais por trás de alguns problemas sobre os quais a política científica e tecnológica possui governabilidade, por conferir ao Estado um papel fundamental (como de fato sempre foi, na América Latina) e por apresentar uma forte preocupação política (reconhecendo, portanto, a importância das políticas científicas e tecnológicas como indutoras de mudanças econômicas e sociais), o PLACTS oferece um arcabouço mais adequado que o enfoque evolucionário no que se refere à sua aplicabilidade sobre a formulação da PCT.

O último enfoque apresentado e o que parece ser mais adequado como instrumento de apoio à formulação, implementação e avaliação de políticas na área de ciência e tecnologia na América Latina é aquele fornecido pela visão alternativa. Essa visão procura criar um arcabouço teórico-conceitual capaz de apoiar, por meio da PCT, a construção de uma 
sociedade radicalmente distinta da atual. É, portanto, muito diferente do enfoque evolucionário e do PLACTS.

A distinção mais significativa, do ponto de vista ideológico, que pode ser percebida entre a visão alternativa e os outros dois enfoques aqui apresentados remete à questão da posse dos meios de produção. Tanto o enfoque evolucionário quanto o PLACTS (de um modo geral) não enxergam essa questão como um problema. Por outro lado, essa questão de fato representa uma das principais preocupações da visão alternativa.

Por entender que um determinado estilo de sociedade só pode ser sustentado por um padrão científico e tecnológico compatível, em termos de valores, a visão alternativa propõe uma mudança profunda no padrão atual da política científica e tecnológica e, mais que isso, no modo de fazer ciência e tecnologia. Justamente por vislumbrar mudanças mais profundas sobre a sociedade, a partir da ciência e da tecnologia, a visão alternativa parece ser mais interessante para os países da América Latina, fortemente marcados pelos constrangimentos colocados pelo processo histórico da formação do capitalismo periférico.

\section{Referências}

BIJKER, W. E. (1995). Of bicycles, bakelites, and bulbs: toward a theory of sociotechnical change. Massachusetts: MIT Press.

BOZEMAN, B. \& SAREWITZ, D. (2005) "Public values and public failure in U.S. science policy”. Science and Public Policy 31 (2).

CUTCLIFFE, S. (2003) Ideas, máquinas y valores - los estudios de ciencia, tecnología y sociedad. México, D.F.: Anthropos Editorial.

DAGNINO, R. P. et al. (1996) "El pensamiento en ciencia, tecnología y sociedad en latinoamérica: una interpretación política de su trayectoria”. II Jornada Latinoamericana de Estudios Sociales de la Ciencia y la Tecnología.

DAGNINO, R. P. (2004) “A relação pesquisa-produção: em busca de um enfoque alternativo”. In SANTOS, L. W. et al. (orgs). Ciência, tecnologia e sociedade: o desafio da interação. Londrina: IAPAR.

DAGNINO, R. P. et al. (2004) "Sobre o marco analítico-conceitual da tecnologia social”. In FUNDAÇÃO BANCO DO BRASIL Tecnologia social: uma estratégia para o desenvolvimento. Rio de Janeiro: Fundação Banco do Brasil.

DIAS, R. \& DAGNINO, R. P. (2006) "Políticas de ciência e tecnologia: sessenta anos do relatório 'Science: the endless frontier". Avaliação 11 (2).

DOSI, G. (1982). “Technological paradigms and technological trajectories: a suggested interpretation of the determinants and directions of technological change". Research Policy 11 (3). 
DOSI, G. et al. (eds.) (1988) Technical change and economic theory. Londres: Pinter Publishers.

ETZKOWITZ, H. \& LEYDESDORFF, L. (1997) "Universities in the global knowledge economy”. In ETZKOWITZ, H. \& LEYDESDORFF, L. (eds.) Universities and the global knowledge economy: a triple helix of university - industry - government relations. Londres: Pinter Publishers.

FEENBERG, A. (1991) Critical theory of technology. Oxford: Oxford University Press.

FEENBERG, A. (2003) “O que é a filosofia da tecnologia?". URL [On line]: www-rohan.sdsu.edu/faculty/feenberg/oquee.htm. Acesso em: $10 \mathrm{de}$ janeiro de 2007.

FREEMAN, C. \& PEREZ, C. (1988) "Structural crises of adjustment: business cycles and investment behaviour”, In DOSI, G. et al. Technical change and economic theory. Londres: Pinter Publishers.

HAVAS, A. (2004) "Policy schemes fostering the creation and exploitation of knowledge for economic growth: the case of Hungary". IPED Conference, Varsóvia.

HERRERA, A. (1973) “Los determinantes sociales de la política científica en América Latina - política científica explícita y política científica implícita”. Desarrollo Económico 13 (49).

HUGHES, T. (1986) “The seamless web: technology, science, etcetera, etcetera”. Social Studies of Science 16 (2).

KREIMER, P. \& THOMAS, H. (2004) "Un poco de reflexividad o ¿de dónde venimos? Estudios sociales de la ciencia y la tecnología en América Latina”. In KREIMER, P. et al. (eds). Producción y uso social de conocimientos: estudios de sociología de la ciencia y la tecnología en América Latina. Buenos Aires: Universidad Nacional de Quilmes Editorial.

KWASNICKI, W. (2003) "Schumpeterian modelling". URL [On line]: prawo.uni.wroc.pl/ kwasnicki/todownload/Schumpeterianmodelling.pdf. Acesso em: 10 de janeiro de 2007.

LOPES, J. L. (1964) Ciência e desenvolvimento. Rio de Janeiro: Edições Tempo Brasileiro.

LOPES, J. L. (1978) Ciência e libertação. Rio de Janeiro: Paz e Terra.

LÓPEZ, A. F. (1996) "Las ideas evolucionistas en Economía: una visión de conjunto". Revista Buenos Aires Pensamiento Económico 1 (1).

LÓPEZ CEREZO, J. A. (2004) "Ciência, tecnologia e sociedade: o estado da arte na Europa e nos Estados Unidos”. In SANTOS, L. W. et al. (orgs). Ciência, tecnologia e sociedade: o desafio da interação. Londrina: IAPAR.

LUKES, S. (1974) Power: a radical view. Londres: Macmillan.

MÉSZÁROS, I. (2002) Para além do capital. Campinas: Editora da Unicamp.

NELSON, R. R. (1994) "Economic growth via the coevolution of technology and institutions". In LEYDESDORFF, L. \& VAN DEN BESSELAAR, P. (eds). Evolutionary economics and chaos theory: New Directions in Technology Transfer. Londres: Pinter Publishers. 
NOBLE, D. (2001) La locura de la automatización. Barcelona: Alikornio Ediciones.

NOVAES, H. T. (2005) Para além da apropriação dos meios de produção? O processo de adequação sócio-técnica em fábricas recuperadas. Campinas: dissertação de mestrado, Unicamp, Programa de Pós-Graduação em Política Científica e Tecnológica.

OLIVEIRA, M. B. (2002) "Sobre o significado político do positivismo lógico". Crítica Marxista, São Paulo, 14(1).

SCHUMPETER, J. A. (1984) Capitalismo, socialismo e democracia. Rio de Janeiro: Zahar.

SCHUMPETER, J. A. (1988) Teoria do desenvolvimento econômico. São Paulo: Nova Cultural.

VACCAREZZA, L. S. (2004) "Ciência, tecnologia e sociedade: o estado da arte na América Latina”. In SANTOS, L. et al. (orgs). Ciência, tecnologia e sociedade: o desafio da interação. Londrina: IAPAR.

Recebido em: 24 out. 2006 Aceite em: 6 dez. 2006 